\title{
CESARIANA EM ÉGUA - RELATO DE CASO
}

\author{
Jéssica Rodrigues da Silva ${ }^{1}$ \\ Max Gimenez Ribeiro ${ }^{2}$ \\ Carla Faria Orlandini ${ }^{3}$ \\ André Luiz Ladeia ${ }^{4}$ \\ Luciana Vieira Pinto Ribeiro \\ Guilherme Paes Meirelles ${ }^{6}$ \\ José Ricardo Cardozo Barreto Filho
}

SILVA, J. R. da; RIBEIRO, M. G.; ORLANDINI, C. F.; LADEIA, A. L.; RIBEIRO, L. V. P.; MEIRELLES, G. P.; BARRETO FILHO, J. R. C. Cesariana em égua - relato de caso. Arq. Ciênc. Vet. Zool. UNIPAR, Umuarama, v. 17, n. 2, p. 131-137, abr./jun. 2014.

RESUMO: O termo distocia refere-se ao trabalho de parto anormal, e a espécie equina possui baixa incidência em relação às outras espécies. Quando diagnosticada, a correção da estática fetal por meio de manobras obstétricas é o primeiro método sugerido, porém quando não efetiva, a retirada cirúrgica pode ser indicada. A cesariana classifica-se em cesariana de emergência, de semiemergência e semieletiva, sendo que diferentes acessos à cavidade podem ser utilizados para esse procedimento. Descreve-se um caso de cesariana em uma égua de seis anos de idade que apresentava distocia há mais de doze horas e após tentativa sem sucesso de reposicionamento fetal, o animal foi encaminhado à cirurgia. Não houve intercorrências na recuperação anestésica e curativo local foi feito diariamente, juntamente com aplicação de antibióticos e anti-inflamatórios não esteroidais. Devido à hemorragia uterina que o animal passou a apresentar no terceiro dia de pós-operatório foi realizada transfusão sanguínea, administração de antifibrinolítico hemostático e estimulante de células vermelhas. No $17^{\circ}$ dia pós-cirúrgico a égua recebeu alta e após cinco meses da data de cirurgia, por meio de ultrassonografia transretal, constatou-se que a égua apresentava um folículo de 37 milímetros no ovário direito. Conclui-se com esse relato que a cesariana em éguas é aplicada com sucesso nos casos de distocia, porém mais trabalhos, maior número de estudos e relatos sobre esse tema precisam ser feitos para que se possa estipular a taxa de sucesso deste procedimento nesta espécie e também a taxa de fertilidade futura das éguas.

PALAVRAS-CHAVE: Cirurgia. Cesárea. Distocia. Potro.

\section{CESAREAN SURGERY IN MARES - A CASE STUDY}

ABSTRACT: Dystocia is a term referred to an abnormal labor with relatively low incidence in horses. When diagnosed, the first suggested procedure is the correction of the fetal position through obstetric maneuvers. However, when these are not effective, a cesarean section surgery may be indicated. This surgery can be classified as an emergency c-section, semi-emergency c-section or semi-elective c-section, with different approaches to the cavity being performed. A 6-year-old Mangalarga Marchador mare presented dystocia for more than 12 hours, rupture of the corioalantoid membrane and fetal appendages insinuated into the rima vulvae. After unsuccessful fetal repositioning, the animal was submitted to a c-section with median-line incision, uterine exteriorization, uterine incision and removal of the dead fetus. There were no complications during anesthesia or recovery. Bandages were daily changed, and antibiotics and nonsteroidal anti-inflammatory drugs were also administered. Due to a uterine hemorrhage three days after surgery, the animal received blood transfusion, antifibrinolytic drugs and red blood cell stimulating agents. On the $17^{\text {th }}$ day after surgery, the animal was discharged. Five months after the surgery, a trans-rectal ultrasound showed a 37-milimiter follicle in the right ovary. It can be concluded from this report that cesarean section in mares can be successfully applied in cases of dystocia, but further research and studies on this subject are needed in order to determine the success rate of this procedure in this species, as well as the rate of future fertility of these mares.

KEYWORDS: Surgery. Cesarean section. Dystocia. Foal.

\section{CESÁREA EN YEGUA - RELATO DE CASO}

RESUMEN: El término distocia se refiere al trabajo de parto anormal, y la especie equina tiene baja incidencia en relación a otras especies. Cuando diagnosticada, la corrección de la estática fetal por medio de maniobras obstétricas es el primer método sugerido, pero, cuando no efectiva, la retirada quirúrgica puede ser indicada. La cesárea se clasifica en: de emergencia, de semiemergencia y semielectiva, siendo que diferentes accesos a la cavidad pueden ser utilizados para ese procedimiento.

DOI: https://doi.org/10.25110/arqvet.v17i2.2014.4931

${ }^{1}$ Residente de clínica médica e cirúrgica de grandes animais - Universidade Federal do Paraná - Curitiba/PR. jerodrigues_vet@yahoo.com.br. Endereço: Rua dos Funcionários, 1540, Juveve, Curitiba - PR

${ }^{2}$ Professor Associado Curso Medicina Veterinária - Universidade Estadual de Maringá - Umuarama/PR.

${ }^{3}$ Mestranda em ciência animal - Universidade Paranaense - Umuarama/PR;

${ }^{4}$ Médico veterinário da Agropecuária Sinal Rural - Douradina/PR;

${ }^{5}$ Professora do curso de Medicina Veterinária - Universidade Paranaense - Umuarama/PR;

${ }^{6}$ Residente de anestesiologia veterinária - Universidade Federal do Paraná - Curitiba/PR;

${ }^{7}$ Médico Veterinário Clínica M.A.I.S Veterinary Team - Clube Hípico Santo Amaro - São Paulo/SP. 
Se describe un caso de cesárea un una yegua de seis años de edad que presentaba distocia hacia más de doce horas y después de tentativas sin logro de reposicionamiento fetal, el animal fue encaminado a la cirugía. No hubo complicaciones en la recuperación anestésica y diariamente ha sido hecho curativo en el local, juntamente con aplicación de antibióticos y antiinflamatorios no esteroides. Debido a la hemorragia uterina que el animal pasó a presentar en el tercer día de posoperatorio se realizó transfusión sanguínea, administración de antifibrinolítico hemostático y estimulante de células rojas. En el $17^{\circ}$ día posquirúrgico la yegua recibió alta y después de cinco meses de la fecha de la cirugía, por medio de ecografía transrectal, se ha constatado que la yegua presentaba un folículo de 37 milímetros en el ovario derecho. Se ha concluido con ese relato que la cesárea en yeguas es aplicada con éxito en casos de distocia, todavía, más estudios y relatos sobre ese tema necesitan ser hechos para que se pueda estipular la tasa de éxito de este procedimiento en esta especie y también la tasa de fertilidad futura de las yeguas.

PALABRAS CLAVE: Cirugía. Cesárea. Distocia. Potro.

\section{Introdução}

O termo distocia refere-se ao trabalho de parto anormal. É considerado uma real emergência em éguas (LU et al., 2006) e pode ter origem fetal ou materna. Dentre as causas de origem materna estão deformidades pélvicas, torção uterina e defeitos na parede abdominal, tais como ruptura do tendão pré-púbico e hérnia inguinal. Nas causas de origem fetal podemos incluir postura fetal anormal, anormalidades estruturais e infecções fetais (COLAHAN et al., 1999). Segundo White e Moore (1998) a incidência de distocia em éguas é relativamente baixa quando comparada às outras espécies animais (cerca de 1 a 4\%). Lu et al. (2006) também relatam uma baixa taxa de ocorrência, com valores variando entre 1 e $10 \%$. Mesmo ocorrendo em menos de $10 \%$ dos casos, as distocias podem causar grande impacto econômico na indústria equina. O diagnóstico precoce desta afecção é importante, tanto para salvar a vida do potro quanto para preservar a capacidade reprodutiva da égua (WHITE; MOORE, 1998).

Os motivos da reduzida incidência de distocia nesta espécie estão relacionados ao parto que é rápido (EMBERTSON, 2002), comumente noturno e com rápido deslocamento placentário, e também à estrutura anatômica da pelve da égua que é curta, de abertura circular e de parede plana, não dificultando a saída do feto (PRESTES; LANDIM-ALVARENGA, 2005).

Quando há diagnóstico de parto distócico, a correção da apresentação anormal do potro por meio de manobras obstétricas é o primeiro método indicado para corrigir a distocia (LU et al., 2006) e, para tanto, a distensão uterina com fluidos pode ser benéfica (WHITE; MOORE, 1998). Segundo White e Moore (1998), em casos em que a manobra obstétrica não obtém bons resultados, a cesariana é indicada e deve ser realizada o mais rápido possível.

O termo 'cesariana' originou-se da expressão latina "caesa matris utero", que significa "corte do útero materno". Trata-se de uma laparotomia com histerotomia, que tem por finalidade a retirada do feto, sendo um ou mais, vivo ou morto, e pode ser classificada como conservativa, retirada do feto sem o útero, ou radical, que é a retirada do feto com o útero, denominada histerectomia (TONIOLLO; VICENTE, 2003). As indicações desta cirurgia podem ser divididas de acordo com a urgência da situação em: cirurgia de emergência, cirurgia de semi-emergência e cirurgia semi-eletiva (WHITE; MOORE, 1998); (AUER; STICK, 1999). A cesárea de emergência é indicada quando a ruptura da membrana corioalantoideana ocorreu há mais de 45 a 60 minutos e quando há dificuldade de palpação do tórax do potro para avaliação dos batimentos cardíacos. É recomendada também quando a égua apresenta um curto prazo de vida ou uma condição potencialmente fatal, como uma torção uterina (WHITE; MOORE, 1998), (AUER; STICK, 1999). A cesariana considerada de semi-emergência é indicada quando a ruptura do corioalantóide ocorreu há mais de três ou quatro horas e o potro já está morto. Devemos levar em conta que esse tipo de acontecimento pode afetar não só a taxa de sobrevivência da égua, mas também sua saúde e potencial reprodutivo futuro. A indicação mais comum para essa classificação de cirurgia é quando há distocia e não se sabe se o feto está vivo ou morto (WHITE; MOORE, 1998), (AUER; STICK, 1999). As cesarianas consideradas semi-eletivas incluem as cirurgias planejadas, utilizadas para retirada de potros com fins de investigação e também nos casos em que há presença de distocia antecipada ou significante trauma reprodutivo (WHITE; MOORE, 1998), (AUER; STICK, 1999). Segundo White e Moore (1998), os traumas podem ser causados por fratura de pelve e/ou tumores, ou ainda quando a égua encontra-se em estágio terminal e há um grande interesse em salvar o potro. Exemplos desta última incluem égua em decúbito resultante de anormalidades neurológicas, laminite severa, condições debilitantes e potencialmente fatais e também em casos em que a eutanásia é planejada. Em contraste com a cesariana de emergência, que é baseada geralmente em distocia e baixa taxa de sobrevivência do potro, as cesáreas eletivas são bem planejadas e resultam em uma taxa bem maior de sobrevivência da prole (AUER; STICK, 1999).

As abordagens mais comuns da cirurgia cesariana são através da linha média ventral, linha paramediana (ROBINSON, 2003), acesso pelo flanco baixo modificado, acesso paracostal e vertical pelo flanco. A abordagem vertical pelo flanco é utilizada quando há edema ventral excessivo ou quando o animal encontra-se à campo e a intenção é a recuperação apenas do potro, seguida de eutanásia da égua. Este acesso possibilita uma exposição muito limitada do campo cirúrgico, podendo levar a trauma muscular severo e a o procedimento realizado com a égua em estação não é indicado, pois há grande chance do animal cair, ocorrendo protrusão das vísceras e contaminação das mesmas (AUER; STICK, 1999). A abordagem pela linha mediana ventral, por sua vez, é utilizada mais comumente em ambiente hospitalar, onde se espera boa recuperação do potro e da égua (ROBINSON, 2003). Segundo White e Moore (1998), esta última é a melhor técnica, pois permite uma maior exposição das alças e também por ser um acesso mais familiar ao cirurgião. No processo cirúrgico, o corno uterino gravídico que contém os membros torácicos deve ser localizado e exteriorizado. Um ou dois pontos de ancoragem podem ser feitos para evitar contaminação da cavidade abdominal com o conteúdo ute- 
rino. Uma incisão estreita deve ser feita através da parede uterina e da placenta e deve ser suficientemente longa para possibilitar a retirada do feto sem que haja ruptura uterina. Durante a retirada, os membros devem ser protegidos para que não entrem em contato com os campos, evitando uma possível contaminação. Nesta manobra o feto deve ser rapidamente retirado do útero e o cordão umbilical rompido próximo ao corpo do potro. Caso a placenta possa ser facilmente separada do útero, esta deve ser removida neste momento (AUER; STICK, 1999). Após tais manobras, o útero deve ser suturado com a utilização de dois planos de sutura, sendo a primeira camada do tipo simples contínua seguida por uma invaginante ou um primeiro plano de sutura do tipo invaginante seguida por uma sutura Lembert, ambas com fio absorvível número 2. Após sutura, a porção uterina que foi exposta durante a cirurgia pode ser lavada com solução salina, preferencialmente aquecida. Após o término da lavagem, o cirurgião deve trocar as roupas e as luvas cirúrgicas. $\mathrm{O}$ abdômen pode ser lavado com solução salina aquecida e soluções de antibiótico podem ser instiladas dentro da cavidade antes da sutura da parede abdominal (AUER; STICK, 1999).

Os cuidados pós-operatórios de uma égua que foi submetida à cesariana são muito similares àqueles feitos em qualquer cirurgia abdominal, porém com uma especial atenção ao trato reprodutivo. É importante que haja expulsão da placenta após a recuperação anestésica, quando esta não é retirada durante o procedimento cirúrgico. Antibióticos sistêmicos devem ser administrados por três a cinco dias, variando conforme a contaminação e trauma cirúrgicos (SAINI et al. 2013); (EMBERTSON, 2002). Flunixina meglumina também deve ser administrada durante este período, para diminuir o edema e neutralizar o efeito de potencial endotoxemia. Soluções intravenosas podem ser utilizadas para manutenção da hidratação, do equilíbrio ácido básico e correção de eletrólitos quando for necessário (EMBERTSON, 2002). A alimentação pós-operatória deve ser feita baseada na prevenção de problemas intestinais como íleo paralítico e constipação, mesmo quando não há manipulação das alças durante o procedimento. Água e forragem verde devem ser oferecidas a vontade, sendo o feno e os cereais reintroduzidos gradualmente à alimentação. $\mathrm{O}$ exercício consiste em pequenas caminhadas guiadas pelo cabresto, de três a quatro vezes por dia, iniciando no dia após a cirurgia (AUER; STICK, 1999).

Como em todo procedimento cirúrgico, complicações podem ocorrer após a cirurgia cesariana embora, geralmente, sejam consequentes aos traumas causados durante a distocia, antes da cirurgia. Dentre os problemas que podem ocorrer estão inclusos traumas intestinais, estes por vez podem ocasionar contusões severas resultando em cólica por compactação ou por necrose intestinal. Quando a cirurgia é realizada em um tempo apropriado, há diminuição da incidência de problemas reprodutivos pós-operatórios. Esforço físico no pós-parto também deve ser evitado, pois pode causar prolapso de bexiga ou uterino. Outras complicações relacionadas diretamente ao ato cirúrgico da cesariana incluem infecção incisional, deiscência de pontos e acidentes anestésicos (AUER; STICK, 1999). Hemorragia uterina causada pela incisão deste órgão é a principal causa de morte materna, ocorrendo em até $35 \%$ dos casos. (BISWAS et al., 2012). Outras causas de morte da égua incluem hemorragia vaginal, choque, evisceração, laminite, fratura ileosacral, deiscência dos pontos da histerotomia com consequente peritonite (AUER; STICK, 1999) e infecção de órgãos adjacentes (BISWAS et al., 2012). Técnicas cirúrgicas atualizadas, medicação pré e pós-operatória e cuidados de enfermagem em um ambiente hospitalar tem diminuído a taxa de mortalidade das éguas (AUER; STICK, 1999).

Após a cesariana, a taxa de fertilidade da égua diminui consideravelmente. Éguas que passaram por um processo cirúrgico como este possuem uma média de partos em torno de $35 \%$. A taxa de parição para éguas submetidas à tal procedimento nos Estados Unidos, geralmente varia entre 50 e $65 \%$. Quando há um bom manejo reprodutivo a taxa pode ser de até $70 \%$ ou mais (AUER; STICK, 1999). Segundo os mesmos autores a diminuição da fertilidade pode ocorrer por aderências uterinas, por inabilidade da parede uterina em se adaptar ao crescimento fetal, por destruição endometrial focal e traumas em outras áreas do trato reprodutivo das éguas. Grunert e Birgel (1982) afirmam que apesar de, na maioria das vezes, serem bem sucedidas, o prognóstico em cesarianas em éguas é menos favorável do que o observado nos bovinos.

\section{Relato do Caso}

No dia 02 de agosto de 2012, foi enviada ao Hospital Veterinário de Grandes Animais da Universidade Estadual de Maringá - HVGA/UEM, no Centro de Ciências Agrárias (CCA) localizado na cidade de Umuarama, Paraná, uma égua de pelagem tordilha, de seis anos de idade, $400 \mathrm{~kg}$, da raça Mangalarga Marchador. Ao chegar ao HVGA/UEM o animal foi prontamente atendido pela equipe de médicos veterinários, que constataram, através do exame clínico e físico, que o animal apresentava ruptura da membrana corioalantoideana, com insinuação dos anexos fetais na rima vulvar, sem odor fétido ou elementos contaminantes. Segundo o proprietário e responsável, a égua apresentava distocia há mais de doze horas e na propriedade haviam manipulado o feto numa tentativa de reposicionamento, porém, sem sucesso. No decorrer do exame físico, pode-se observar que o animal apresentava mucosas congestas e secas, tempo de preenchimento capilar de 3 segundos, elasticidade da pele diminuída e olhos fundos. A partir dessas observações instituiu-se imediatamente a fluidoterapia e optou-se por fazer a manobra obstétrica, com auxílio da carboximetilcelulose ${ }^{1}$, na tentativa de reposicionar o potro. Através da palpação transvaginal, realizada durante o processo (Figura 1), observou-se que o potro estava sem vida e, por isso, todas as opções quanto ao tratamento foram tomadas visando o melhor apenas para a saúde da égua.

${ }^{1}$ Carboximetilcelulose, Farmanilquímica, Curitiba - PR. 


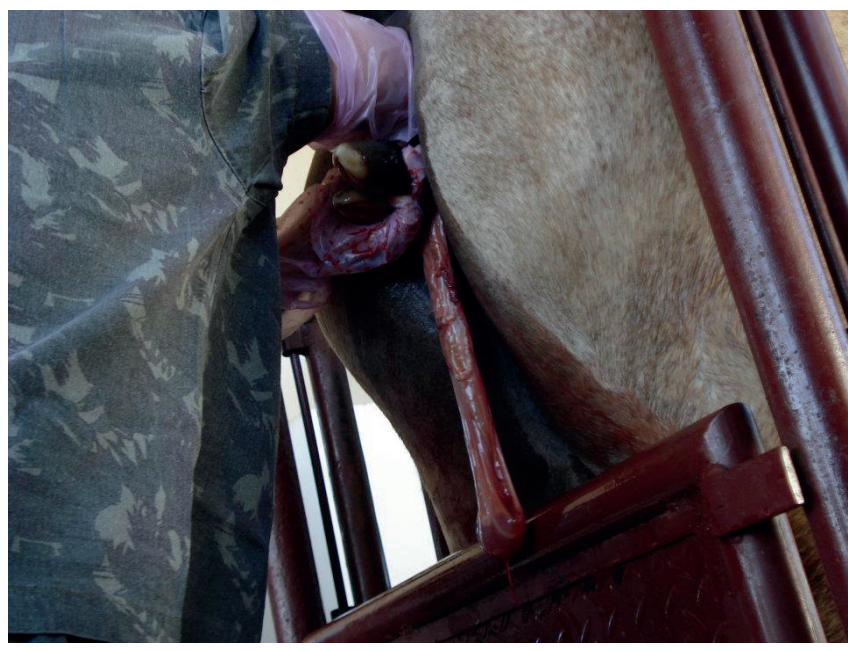

Figura 1: Tentativa de correção da estática fetal através da palpação transvaginal em égua. Fonte: Do autor.

Como não houve sucesso na manobra obstétrica e devido ao grande tempo de distocia, o tratamento sugerido ao proprietário foi o cirúrgico, através da retirada do potro por meio de cesariana. Após liberação e autorização por escrito do proprietário, o animal foi então preparado para entrar no centro cirúrgico, onde seria realizado o procedimento.

O protocolo anestésico previu sedação com xilazi$\mathrm{na}^{2} 1 \mathrm{mg} / \mathrm{kg}$, indução com midazolam ${ }^{3} 0,05 \mathrm{mg} / \mathrm{kg}$ e cetami$\mathrm{na}^{4} 2,2 \mathrm{mg} / \mathrm{kg}$ associados e administrados IV. Após a indução anestésica, foi entubada com tubo endotraqueal ${ }^{5}$ número 22 , e o plano anestésico foi mantido com uso de anestésico inalatório isoflurano ${ }^{6}$ associado a oxigênio $100 \%{ }^{7}$, como citado por Embertson ( 2002). A égua foi colocada em decúbito dorsal e, após estabilização anestésica, foi feita ampla tricotomia no abdômen, na região da linha Alba, seguida por higienização e anti-sepsia local. Pela facilidade da localização uterina e por proporcionar uma melhor exposição visceral, o acesso foi feito através de uma incisão de pele na linha média ventral. Após abertura da cavidade, o útero foi localizado, exteriorizado e isolado por meio de compressas e panos de campo. Com a utilização de um bisturi, realizou-se incisão uterina (Figura 2), seguida de incisão da placenta e membrana amniótica, com posterior tração e retirada do feto, sendo o cordão umbilical imediatamente rompido.
${ }^{2}$ Sedomin, Nutrivet, Jaguariúna - SP.

${ }^{3}$ Midazolam, Dimensão Hospitalar, Umuarama - PR.

${ }^{4}$ Cetamim, Nutrivet, Jaguariúna - SP.

${ }^{5}$ Tubo endotraqueal, Cisne Materiais Hospitalares, Umuarama - PR.

${ }^{6}$ Vetflurano, Dimensão Hospitalar, Umuarama - PR.

${ }^{7}$ Oxigênio $100 \%$, Oxirama, Umuarama - PR.

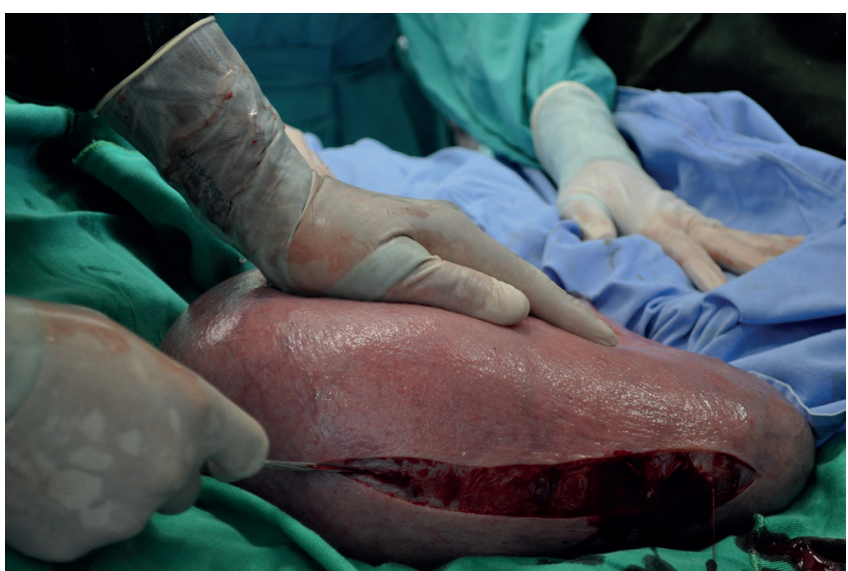

Figura 2: Incisão uterina em égua para retirada do feto. Fonte: Do autor.

Para tal manobra o útero foi pinçado em sua curvatura maior em um ponto que foi utilizado como ponto de ancoragem. Este momento exigiu especial atenção da equipe auxiliar, que cooperou na retirada do potro e em sua correta manipulação. O cirurgião auxiliar neste momento foi responsável por segurar o ponto de ancoragem. Após a retirada do feto, a placenta foi removida por tração manual leve, o útero foi suturado em dois planos, sendo o primeiro feito através de uma linha de sutura simples contínua com fio absorvível não sintético, Catgut 2, e em segundo plano com uma sutura do tipo invaginante em padrão Cushing, também com Catgut 2, para então ser reposicionado na cavidade abdominal. A sutura da musculatura e peritônio foi feita com fio não absorvível sintético, polipropileno ${ }^{8} 2$, em padrão Sultan. O subcutâneo foi suturado com Catgut ${ }^{9} 1$ em ziguezague e a pele também com polipropileno 2, com pontos do tipo simples isolado, em padrão Wolf. Finalizada a sutura, foi feito curativo local com digluconato de clorexidine $2 \%{ }^{10}$ e pomada cicatrizante ${ }^{11}$ no local da incisão.

Durante a recuperação anestésica não houve intercorrências. Após levantar o animal foi levado e mantido em uma baia do HVG/UEM, com água ad libitum e alimentação restrita ao fornecimento de forragem verde. Os curativos foram feitos diariamente através de ducha local por 30 minutos com água corrente, limpeza com uso de digluconato de clorexidine degermante a $2 \%$ com gaze e compressas estéreis e pomada cicatrizante. Era realizado enfaixamento diário com a utilização de atadura crepe ${ }^{12}$ de $30 \mathrm{~cm}$ de largura na linha de incisão para proteger a cicatriz de moscas e também de vestígios de cama, caso o animal viesse a deitar.

A medicação pós-operatória consistiu na aplicação intramuscular (IM) de benzilpenicilina procaína, diidroestreptomicina e procaína associados ${ }^{13}$ na dose de 10.000 UI para cada $20 \mathrm{~kg} \mathrm{SID}$, por um período de sete dias; gentamicina $^{14}$ na dose de $4 \mathrm{mg} / \mathrm{kg}$ diluída em soro e feita IV, SID, durante sete dias, aplicação IV de flunixina meglumina ${ }^{15}$

\footnotetext{
${ }^{8}$ Polipropileno, Ethicom- Johnson \& Johnson do Brasil- SP.

${ }^{9}$ Catgut, Ethicom- Johnson \& Johnson do Brasil.

${ }^{10}$ Riohex, Rioquímica - SP.

${ }^{11}$ Alantol, Vetnil - SP.

${ }^{12}$ Atadura crepe, Cisne Materiais Hospitalares, PR.

${ }^{13}$ Benzilpenicilina procaína, diidroestreptomicina e procaína, Vallée produtos veterinários - SP.

${ }^{14}$ Gentamicina, CHEMITEC AGRO-VETERINÁRIA LTDA - SP.

${ }^{15}$ Flunixina meglumina, msd-saude-animal - SP.
} 
com citado por Embertson (2002), na dose de 1,1 mg/kg, por um período de 5 dias e dimetilsufóxido ${ }^{16}$ na dose de 1 $\mathrm{g} / \mathrm{kg}$ diluído em soro, por 3 dias, SID. No terceiro dia de pós-operatório, observou-se grande hemorragia uterina na égua, onde coágulos puderam ser retirados do útero por meio de palpação vaginal. Para facilitar a retirada dos coágulos, efetuou-se lavagem uterina (Figura 3) durante três dias com a utilização de solução fisiológica ${ }^{17}$ aquecida e permanganato de potássio ${ }^{18}$.

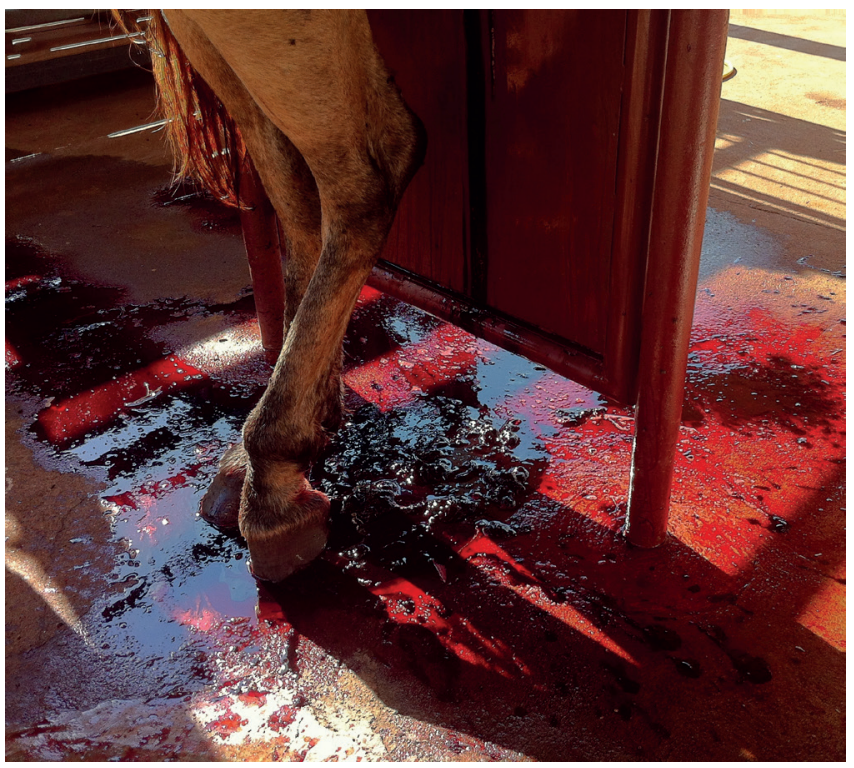

Figura 3: Coágulos retirados após lavagem uterina em égua. Fonte: Do autor.

Considerando-se a grande perda sanguínea por meio de hemorragia, iniciou-se no terceiro dia de pós-operatório a administração de um estimulante de células vermelhas, e para diminuir o quadro hemorrágico, administrou-se duas doses de ácido tranexâmico ${ }^{19}$, um antifibrinolítico hemostático, na dose de $10 \mathrm{mg} / \mathrm{kg}$, SID. Transfusão de seis bolsas de sangue também foi realizada no terceiro dia, já que o hematócrito (HT) da paciente era de $12 \%$, valor considerado abaixo do limite normal para a espécie. No sexto dia de pós-operatório, a hemorragia diminuiu e as lavagens uterinas foram suspensas. A ferida cirúrgica encontrava-se limpa, seca, sem secreção, sem edema e não havia dor à palpação.

Após 15 dias de pós-operatório os pontos de sutura de pele foram retirados e no $17^{\circ}$ dia a égua, por apresentar-se clinicamente estável, recebeu alta e retornou ao haras. Durante os meses seguintes, foi feito um acompanhamento mensal do animal em relação à cicatrização incisional, condição corporal e, com auxílio de ultrassonografia, avaliou-se também o ciclo estral. No sexto mês de pós-operatório, por meio de ultrassonografia transretal, constatou-se que a égua apresentava um folículo de $37 \mathrm{~mm}$ no ovário direito.

\section{Discussão}

A correção da estática do feto, segundo White e Moore (1998), deve ser a primeira opção na tentativa de se des-

\footnotetext{
${ }^{6}$ Dimetilsulfóxido, Marcolab - SP

${ }^{17}$ Solução fisiológica, Dimensão Hospitalar, Umuarama - PR.

${ }^{18}$ Permanganato de potássio, Farmos, Mundo Novo - RJ

${ }^{19}$ Transamin, Dimensão Hospitalar, Umuarama - PR.
}

fazer a distocia de origem fetal e pode ser feita com auxílio de fluidos para causar dilatação uterina. Neste relato a manipulação do feto mal posicionado foi feita com auxílio de carboximetilcelulose, o que ajudou na lubrificação dos membros e facilitou a palpação. Freeman et al. (1999) também citam a utilização de lubrificantes solúveis em água para facilitar a manipulação e retirada do potro distócico. Apesar da tentativa de correção ter sido feita com utilização de lubrificantes, neste relato, tal manobra não obteve sucesso, devido ao mal posicionamento e ao grande tamanho fetal.

Quando feita a palpação transvaginal para avaliação da vitalidade do potro, foi diagnosticada morte do mesmo pela ausência de batimentos cardíacos e, como não houve sucesso na correção da estática fetal, optou-se pela realização do procedimento cirúrgico por meio de cesariana para a retirada do feto morto, precedendo à total recuperação da fêmea. Em levantamento feito por Borges et al. (2006) na Universidade Federal da Bahia sobre casos de distocia em vacas atendidas na clínica de bovinos entre os anos de 1985 e 2003, comprovar demonstrou-se que a cesariana foi o segundo método de correção mais utilizado nos casos de parto distócico. A manobra obstétrica foi o primeiro mais efetuado e a fetotomia o terceiro.

Como o proprietário relatou que a ruptura do corioalantóide havia ocorrido há aproximadamente 12 horas e o potro estava morto, esta foi considerada, segundo Auer e Stick (1999), uma cesariana de semi-emergência. Sabendo dos riscos que a égua corria a equipe cirúrgica fez prontamente o preparo do animal para entrar em cirurgia. Para tanto foi realizado ampla tricotomia, higienização rigorosa, anti-sepsia local, fluidoterapia e medicação necessária, que consistiu em antiinflamatórios não esteroidais e antibioticoterapia sistêmica, como relatam Prestes e Landin-Alvarenga (2005) e Turner e McIlwraith (2002).

Segundo Robinson (2003), na cirurgia cesariana utiliza-se com maior frequência a abordagem cirúrgica pela linha média ventral, pois esta propicia uma boa recuperação da égua e é considerada por White e Moore (1998) como o melhor acesso ao útero, pois promove grande exposição das alças intestinais e é um local mais comum ao cirurgião. Sendo assim, a abertura pela linha mediana foi o acesso escolhido pelo cirurgião e auxiliares e para isso procedeu-se ampla incisão de pele, linha branca e peritônio, atingindo a cavidade abdominal sendo que a incisão estendeu-se da cicatriz umbilical à base das mamas (PRESTES; LANDIM-ALVARENGA, 2005). Corroborando com Auer e Stick (1999), após a exposição das alças e localização do útero, este foi incisado e um ponto de ancoragem foi utilizado com o intuito de evitar possíveis contaminações da cavidade abdominal. Após a incisão ser feita, o feto foi retirado rapidamente e o cordão umbilical rompido próximo ao seu corpo. A placenta foi retirada manual e lentamente, procedimento este também citado pelos mesmos autores.

Para sutura uterina, dois planos foram utilizados, sendo realizada no primeiro plano a sutura do tipo simples contínua e no segundo sutura invaginante em padrão Cushing, visando diminuir a área de atrito entre o fio de sutura e as alças, fazendo com que assim diminuíssem as chances de uma possível aderência entre o útero e os órgãos viscerais no pós operatório (TURNER e McILWRAITH, 2002). Para ambos os planos foi utilizado fio absorvível não sintético, 
Categut número 2. Guidoni et al. (2007) compararam a cicatrização de três diferentes tipos de sutura para histerorrafia em 18 cicatrizes uterinas de coelhas que passaram pelo procedimento de cesariana eletiva no $26^{\circ}$ dia de gestação. As suturas consistiam em pontos separados, contínuos e contínuos ancorados e os métodos de análise utilizados foram avaliação macro e microscópica das áreas suturadas, porém após análise afirmou-se que não houve diferenças estatísticas significantes em relação aos parâmetros avaliados. Turner e McIlwraith (2002) citam que para sutura uterina em éguas o método mais recomendado é uma linha de sutura contínua na linha de incisão para causar, principalmente, hemostasia uterina seguida por uma segunda camada de sutura, sendo esta de inversão das bordas. Segundo estes mesmos autores o fio utilizado para tal procedimento pode ser o Categut número 2, o que justifica a escolha do fio e também o método de sutura invaginante utilizados neste relato de caso.

Problemas relacionados à cirurgia cesariana podem ocorrer, tais como os citados por Freeman et al. (1999) que incluem cólica por compactação, prolapso retal, tromboflebite da jugular, hérnia incisional, hemorragia uterina, hipocalcemia, metrite, ruptura uterina, ruptura vaginal, colite, peritonite, miopatia, isquemia do cólon menor e laceração retrovaginal. Neste relato de caso, a hemorragia uterina foi o maior problema encontrado no pós-operatório, pois diminuiu o número total de hemácias e o valor da porcentagem do hematócrito, causando anemia no animal. Como tratamento de suporte para anemia foi feito transfusão sanguínea, com sangue coletado de outro equino hígido para elevar o valor dos componentes sanguíneos da égua em questão aos valores próximos aos considerados normais para a espécie. A transfusão de sangue também foi citada por Freeman et al. (1999) como tratamento de suporte para éguas que tiveram problemas com hemorragia pós-operatória em cirurgia cesariana.

Freeman et al. (1999) avaliaram 116 éguas que apresentavam parto distócico. Dessas 116, 58 foram submetidas à cirurgia cesariana de emergência e 10 foram submetidas a cesariana eletiva. Das éguas que passaram pela cesariana de emergência, apenas sete vieram a óbito por complicações cirúrgicas, o que resulta em uma taxa de $88 \%$ de sobrevivência. Das 10 éguas submetidas ao procedimento cirúrgico eletivo nenhuma veio a óbito, sendo a taxa de sucesso neste caso de $100 \%$. Sendo assim justifica-se o uso de tal procedimento para a distocia da égua deste relato e sugere-se que maior número de cirurgiões utilize deste método para solucionar distocias, quando a infra-estrutura e o conhecimento da técnica forem de domínio dos mesmos.

O tempo de distocia prolongado do animal deste relato foi considerado um dos fatores de risco para a sobrevivência do mesmo, porém Freeman et al. (1999) também comprovaram em seu levantamento que o tempo de distocia e a duração da anestesia não interferiram na sobrevivência das éguas submetidas ao procedimento cirúrgico de cesariana.

Há poucos dados nacionais sobre a fertilidade futura das éguas submetidas à cesariana (PRESTES; LANDIM-ALVARENGA, 2006), porém Bresciani et al. (2001) relatam que houve retorno ao estro dois meses após este procedimento em uma égua "Miniature horse". Em nosso relato de caso, a égua voltou ao estro apenas seis meses após a cirurgia, o que também foi considerado um excelente resultado já que a fertilidade futura dessas éguas é pouco conhecida.

\section{Conclusão}

A cesariana em éguas é aplicada com sucesso nos casos de distocias tanto de origem fetal quanto de origem materna, sendo necessária a escolha correta do local onde o procedimento será realizado. Neste trabalho obtivemos sucesso no tratamento cirúrgico da distocia de origem fetal, que consistiu em cesariana por laparotomia pela linha média ventral, e também no tratamento dos problemas ocasionados por este procedimento, que neste relato foi hemorragia uterina. Por ser um procedimento considerado pouco frequente, mais trabalhos, maior número de estudos e relatos de casos sobre cesariana em éguas precisam ser feitos, para que se possa estipular a taxa de sucesso deste procedimento nesta espécie e também a taxa de fertilidade futura das éguas submetidas à esta opção de tratamento.

\section{Referências}

AUER, J. A.; STICK, J. A. Equine surgery. 4. ed. St. Louis: Saunders, 2012. 1609 p.

BISWAS, S. P.; HALDER, S.; SHIRIN, F. B. Indication and outcome of relaparotomy after caesarean section. Bang Medicine Journal, Khulna, v. 45, p.19-23, 2012

BORGES, M. C. B. et al. Caracterização das distocias atendidas no período de 1985 a 2003 na Clínica de Bovinos da Escola de Medicina Veterinária da Universidade Federal da Bahia. Revista Brasileira de Saúde e Produção Animal, v. 7, n. 2, p. 87-93, 2006.

BRESCIANI, K. D. S. et al. Ocorrência de distocia em fêmea "Miniature horse". ARS Veterinária, v. 17, n. 1, p. 28-31, 2001.

\section{COLAHAN, P. T. et al. Equine medicine and surgery. 5.} ed. Mosby: 1999. 2 v.

EMBERTSON, R. M. Indications and surgical techniques for caesarean section in the mare. Equine Veterinary Education, Malden, v. 5, p. 60-64, 2002.

FREEMAN, D. E. et al. Caesarean section and other methods for assisted delivery: comparison of effects on mare mortality and complications. Equine Veterinary Journal, v. 31, n. 3, p. 203-207, 1999.

GRUNERT, E.; BIRGEL, E. H. Obstetrícia Veterinária. 3. ed. Porto Alegre: Sulina, 1982. 323 p.

GUIDONI, R. G. R. et al. Avaliação anatomopatológica de cicatrizes uterinas de acordo com o tipo de sutura cirúrgica (modelo experimental). Revista Brasileira de Ginecologia e Obstetrícia, v. 29, n. 12, p. 633-638, 2007.

LU, K. G. et al. Dystocia - A true equine emergency. Clinical Techniques in Equine Practice, v. 5, p. 145-153, 2006. 
PRESTES, N. C., LANDIM-ALVARENGA, F. C.

Obstetrícia Veterinária. ed. Rio de Janeiro: GK -

Guanabara Koogan, 2005, 272 p.

ROBINSON, N. E. Current therapy in equine medicine.

5. ed. St. Louis: Elsevier, 2003. 929 p.

SAINI, N. S. et al. Surgical correction of uterine torsion and mare-foal survival in advance pregnant equine patients. Journal of Equine Veterinary Science, v. 33, p. 31-34, 2013.

TONIOLLO G. H., VICENTE W. R. R. Manual de Obstetrícia Veterinária. São Paulo: Varela, 2003. 124 p.

TURNER, A. S.; McILWRAITH, C. W. Técnicas cirúrgicas em animais de grande porte. São Paulo: Roca, 2002. $341 \mathrm{p}$.

WHITE, N. A.; MOORE, J. N. Current techniques in equine surgery and lameness. 2 ed. Philadelphia: Saunders Company, 1998. $692 \mathrm{p}$.

Recebido em: 23/12/2013

Aceito em: 02/05/2014 